\title{
Lex Damni vs. Lex Societatis en la aplicación de la ley francesa del deber de vigilancia de las empresas matrices sobre sus filiales: crónica de un diálogo necesario
}

\author{
Lex Damni vs. Lex Societatis in the Application of the French Law \\ on the Corporate Duty of Vigilance of Parent Companies on their \\ Subsidiaries: Chronicle of a Necessary Dialogue
}

\author{
Antonia Durán Ayago \\ Profesora Titular de Derecho Internacional Privado \\ Universidad de Salamanca \\ aduran@usal.es
}

\begin{abstract}
Sumario: I. Con carácter introductorio.-II. Ley francesa sobre el deber de vigilancia de las empresas matrices sobre sus filiales y sociedades dependientes: objetivo y caracteres.-III. Responsabilidad por daños causados por filiales y sociedades dependientes de empresas francesas: incidencia en el sistema de DIPr. europeo 1. De dónde venimos y dónde estamos 2. Responsabilidad social empresarial y lex societatis: el debate necesario 3 . El encaje del deber de vigilancia en la lex damni.-IV. A modo de conclusión
\end{abstract}

Resumen: La Ley francesa del deber de vigilancia de las empresas matrices sobre sus filiales ha introducido importantes elementos para el debate, también desde la perspectiva del Derecho internacional privado. En este trabajo se afronta el análisis de la interrelación entre la lex societatis, como reguladora de la responsabilidad social de las empresas y la lex damni, como reguladora de la responsabilidad por el daño causado por las filiales de estas empresas en terceros Estados, y su repercusión para obtener una verdadera reparación del daño causado para las víctimas, cuestión ésta que todavía no se ha allanado lo suficiente, pero que en lo aportado por la Ley francesa encuentra un interesante precedente del que habrá que seguir aprendiendo.

Palabras clave: empresas multinacionales, derechos humanos, responsabilidad civil, deber de vigilancia, lex societatis, lex damni

Abstract: The French Law on the corporate duty of vigilance of parent companies on their subsidiaries has introduced important elements for discussion, also from Private International Law. This paper deals with the analysis of the interrelation between the lex societatis, as a regulator of corporate social 
responsibility and the lex damni, as a regulator of liability for the damage caused by the subsidiaries of these companies in third States, and their repercussion to obtain a true reparation of the damage caused to the victims, an issue that has not yet been sufficiently paved, but that in what contributed by the French Law finds an interesting precedent from which it will be necessary to continue learning.

Keywords: multinational companies, human rights, civil responsibility, duty of vigilance, lex societatis, lex damni

\section{Con carácter introductorio}

Lenta pero progresivamente asistimos a un cambio de paradigma en los negocios internacionales, vinculado estrechamente con la necesidad de que estos se desempeñen en el marco del respeto a los Derechos humanos ${ }^{1}$. Una prueba palpable de este cambio lo encontramos en la aprobación en Francia de la Ley 2017-399, de 27 de marzo de 2017, relativa al deber de vigilancia de las empresas matrices sobre sus filiales ${ }^{2}$. Aunque ya realicé un primer análisis de esta Ley en otro trabajo ${ }^{3}$, uno de los aspectos que considero de interés desarrollar, porque en el anterior sólo quedó esbozado, es el relativo a la necesaria coexistencia y articulación entre la lex societatis y la lex damni a la hora de vehicular acciones contra la empresa matriz por los daños causados por sus filiales en terceros Estados. Pues si complicado es, desde la perspectiva del Derecho internacional privado (en adelante, DIPr.) encontrar un foro idóneo para demandar conjuntamente a la filial y a la empresa matriz por los daños causados por

${ }^{1}$ El marco normativo internacional en el que encuadrar este cambio de paradigma se halla en el Pacto Mundial de las Naciones Unidas - Principios rectores sobre las empresas y los Derechos Humanos, 2011; Líneas Directrices para Empresas Multinacionales de la Organización para la Cooperación y el Desarrollo Económico (OCDE), 2011; Declaración Tripartita de Principios sobre las Empresas Multinacionales y la Política Social de la Organización Internacional del Trabajo (OIT), adoptada por el Consejo de Administración de la Oficina Internacional del Trabajo en su 204. ${ }^{a}$ reunión (Ginebra, noviembre de 1977) y enmendada en sus 279. a (noviembre de 2000), 295. a (marzo de 2006) y 329. (marzo de 2017) y, en el ámbito específico del sector extractivo, los Principios Voluntarios de Seguridad y Derechos Humanos (2000).

2 Acceso el 10 de enero de 2020, https://www.legifrance.gouv.fr/eli/loi/2017/3/27/2017399/jo/texte.

3 Antonia Durán Ayago, «Sobre la responsabilidad de las empresas por violaciones graves de los derechos humanos en terceros países. A propósito de la Ley francesa 2017-399, de 27 de marzo de 2017, relativa al deber de vigilancia de las empresas matrices sobre sus filiales», Anuario español de Derecho Internacional Privado, t. XVIII, 2018, 323-348. 
la primera, cuestión ésta que en la doctrina ha sido la más analizada ${ }^{4}$, sin duda también por su carácter previo, no menos relevante es determinar el derecho a aplicar, puesto que conforme a él deberán determinarse el fundamento y el alcance de dicha responsabilidad.

Para contextualizar la trascendencia de las cuestiones que vamos a tratar, conviene aportar algunos datos. Según el Índice de Trasnacionalización de la Conferencia de las Naciones Unidas sobre Comercio y Desarrollo (UNCTAD), las 100 primeras empresas multinacionales del mundo poseen una media de 500 filiales en más de 50 países. Su estructura de propiedad posee 7 niveles jerárquicos, lo que implica que los eslabones de propiedad con las filiales pueden cruzar hasta 6 fronteras ${ }^{5}$. Ampliando estos datos, según precisa la revista Fortune, en la actualidad hay unas 50.000 empresas multinacionales con 450.000 filiales en el mundo, y aproximadamente 159 de las 500 multinacionales más grandes del mundo tienen su sede matriz en Europa $^{6}$.

${ }^{4}$ La bibliografía sobre esta cuestión comienza a ser importante. Destaco algunos de los trabajos que me han parecido de interés resultado útiles para preparar este artículo: Juan José Álvarez Rubio / Katerina Yiannibas, Human Rights in Business. Removal of Barriers to Access to Justice in the European Union, Routledge, 2017; María Álvarez Torné, «El Derecho Internacional Privado ante las vulneraciones de Derechos humanos cometidas por empresas y respuestas en la UE», Revista Española de Derecho Internacional, vol. LXV (2013), 2, 157 190; Laura García Álvarez, Competencia judicial internacional, daños ambientales y grupos transnacionales de sociedades, Editorial Comares, Granada, 2016; Id, Daños ambientales transnacionales y acceso a la justicia, Dykinson, Madrid, 2016; «Daños privados por contaminación en el tráfico externo: a propósito del caso Akpan vs. Shell (Nigeria)», Cuadernos de Derecho Transnacional, vol. 5, núm. 2 (2013), 548-583; Id., «Las acciones colectivas en los litigios internacionales por daños ambientales», Revista Electrónica de Estudios Internacionales, núm. 30, 2015; Daniel Iglesias Márquez / Stephanie V. Ascencio Serrato, «Las vías de responsabilidad de las empresas multinacionales por daños ambientales. El caso Dutch Shell Nigeria», Revista catalana Dret ambiental, vol. V, núm. 1 (2014), 1-40; José Luis Iriarte Ángel, Negocios internacionales y Derechos humanos, Lección Inaugural del curso académico 2016/2017, Universidad Pública de Navarra, 2016; Maria Chiara Marullo / Francisco Javier Zamora Cabot, (eds.), Empresas y Derechos humanos. Temas actuales, Editoriale Scientifica, Napoli, 2018; Antoni Pigrau Solé / María Álvarez Torné / Antonio Cardesa-Salzmann / María Font i Mas / Daniel Iglesias Márquez / Jordi Jaria i Manzano, Derechos humanos y empresas europeas. Un manual práctico para las organizaciones de la sociedad civil y los defensores de los derechos humanos, 2016; Francisco Javier Zamora Cabot / Jesús García Cívico / Lorena Sales Pallarés (eds.), La responsabilidad de las multinacionales por violaciones de Derechos humanos, Cuadernos de la Cátedra de Democracia y Derechos Humanos, Alcalá de Henares, 2013.

5 UNCTAD, Informe sobre las inversiones en el mundo 2016. Nacionalidad de los inversores: retos para la formulación de políticas, 2016, 8, acceso el 28 de enero de 2020, http:// unctad.org/es/PublicationsLibrary/wir2016_Overview_es.pdf.

${ }^{6}$ Vid. Pigrau Solé, / Álvarez Torné / Cardesa-Salzmann / Font i Mas / Iglesias Márquez. / Jaria i Manzano, Derechos humanos y empresas europeas..., 45. 
Según la OCDE, más de la mitad de las importaciones manufacturadas de todo el mundo son bienes intermedios utilizados en la producción de otros bienes ${ }^{7}$. Apunta la Conferencia de las Naciones Unidas sobre Comercio y Desarrollo (UNCTAD) que aproximadamente el $80 \%$ del comercio internacional puede vincularse actualmente a las redes mundiales de producción de las empresas multinacionales ${ }^{8}$. Y según la Confederación Sindical Internacional, el $60 \%$ del comercio mundial en la economía real depende de las cadenas de suministro de 50 corporaciones, las cuales emplean directamente solo el $6 \%$ de los trabajadores, pero dependen de una fuerza laboral oculta que asciende a 116 millones de personas ${ }^{9}$.

En este contexto marcado por la globalización, la Ley francesa sobre el deber de vigilancia de las empresas matrices sobre sus filiales y sociedades dependientes ha aportado nutrientes del máximo interés para el debate. Se trata de la primera legislación a nivel mundial ${ }^{10}$, que contempla, como obligación vinculante, el deber de vigilancia por parte de las empresas, incluyendo sus filiales, proveedores y subcontratas, con independencia de en qué parte del mundo se encuentren. Esto supone romper con los principios de personalidad jurídica propia y responsabilidad patrimonial separada, acuñados a fuego por el Derecho mercantil, abogando por el deber de vigilancia y el control de dirección, lo que supone un giro radical en la conformación de las responsabilidades en los grupos de empresas, que tiene un significado muy importante para lograr la consecución del respeto a los Derechos humanos por parte de las grandes empresas multinacionales y transnacionales ${ }^{11}$.

Hay que tener en cuenta que en estos casos se suele suceder un patrón. En el ámbito del sector extractivo, las empresas multinacionales suelen tener filiales que desempeñan su actividad en Estados con importantes recursos naturales, pero que son débiles institucionalmente hablando, lo que implica que la tradicional lex loci delicti comissi, anudada en estos casos también a la lex damni, no suele dar buenos resultados. Tampoco en el caso de las empresas transnacionales dedicadas al sector textil que buscan cen-

${ }^{7}$ Acceso el 28 de enero de 2020, http://www.oecd.org/dac/aft/mappingglobalvaluechains_web_usb.pdf.

8 Acceso el 28 de enero de 2020, https://unctad.org/es/paginas/PressRelease. aspx? OriginalVersionID $=113$.

${ }^{9}$ Acceso el 28 de enero de 2020, https://www.ituc-csi.org/supply-chains-resourceshub?lang=en.

${ }^{10}$ Iniciativas que van en la misma dirección se han desarrollado recientemente en Finlandia y Países Bajos. Desarrolladas en https://observatoriorsc.org/avances-en-debida-diligenciaen-materia-de-derechos-humanos-en-la-ue/, acceso el 28 de enero de 2020.

${ }^{11}$ Sobre la diferenciación entre empresas multinacionales y empresas transnacionales, vid. Durán Ayago, «Sobre la responsabilidad de las empresas...», 329-330. 
tros de producción en países en que las condiciones laborales tienen un menor coste y en donde los derechos de los trabajadores son prácticamente inexistentes, puesto que la lex loci laboris y la lex damni también conducen a la aplicación de la legislación del Estado menos protector para los trabajadores.

En ambos casos, surgen importantes dificultades a la hora de exigir responsabilidad por los daños que estas empresas causen ante las autoridades gubernamentales y judiciales del Estado de acogida, a lo que se une la complejidad jurídica de armar acciones extraterritoriales que vayan bien por la omisión del deber de vigilancia de la empresa matriz, bien se amparen en una especie de jurisdicción universal de carácter civil, como lo ha sido hasta hace bien poco la Alien Tort Statute estadounidense, ley federal que otorga competencia a los tribunales federales de Estados Unidos para atender las demandas de responsabilidad civil interpuestas por extranjeros ante violaciones del Derecho internacional consuetudinario o un tratado internacional que vincule a este país ${ }^{12}$.

En este trabajo, tras exponer cuáles son las premisas sobre las que la Ley francesa del deber de vigilancia se asienta, y también sus puntos débiles, constatados tras sus casi tres años de vigencia ${ }^{13}$, nos centraremos en el análisis de las cuestiones de DIPr. que se pueden generar. En esta ocasión, prestando particular atención a la concreción del derecho aplicable a los casos de responsabilidad civil por daños causados por las filiales radicadas en terceros Estados. En concreto, enmarcaremos el debate en torno a si es necesario la conformación de una nueva categoría de norma de conflicto que englobe la responsabilidad social empresarial conjuntamente con la ley aplicable al daño, como ha demandado, entre otros, Pataut ${ }^{14}$, o bastaría con un diálogo inteligente entre la lex societatis y la lex damni.

\section{Ley francesa sobre el deber de vigilancia de las empresas matrices sobre sus filiales y sociedades dependientes: objetivo y caracteres}

Aunque es cierto que esta Ley supuso un salto cualitativo en lo que hasta entonces había venido siendo el papel de los Estados en su implicación para obligar a las empresas a cumplir unos mínimos estándares en el

12 En concreto, su formulación es la siguiente: «The district courts shall have original jurisdiction of any civil action by an alien for a tort only, committed in violation of the law of nations or a treaty of the United States».

13 Entró en vigor el 27 de marzo de 2017.

14 Etienne Pataut, «Le devoir de vigilance - Aspects de droit international privé», Droit Social, núm. 10, 2017, 833-839. 
respeto de los Derechos humanos ${ }^{15}$, también lo es que no ha llegado a ser todo lo que en principio se pensó que fuera ${ }^{16}$. La idea inicial era mucho más ambiciosa, puesto que pretendía posibilitar que la empresa matriz respondiera por los daños que causaran sus filiales y sociedades dependientes, en todos los casos, sin necesidad de justificar que hubiera habido un comportamiento imprudente por parte de la matriz, como responsable última del daño causado. Ante un daño, ambas deberían responder. Se trataba de evitar que los principios de personalidad jurídica propia y responsabilidad jurídica limitada actuaran como dique de contención para hacer responder del daño también a la empresa matriz.

Pero la confrontación con los lobbies empresariales fue tan fuerte que finalmente, $y$ tras tres intentos fracasados ${ }^{17}$, la cuarta versión de la Ley

15 Obligación que consta expresamente, por ejemplo, en los Principios rectores sobre las empresas y los Derechos humanos de Naciones Unidas, en los que se indica que los Estados deben adoptar las medidas apropiadas para prevenir, investigar, castigar y reparar los abusos cometidos por las empresas mediante políticas adecuadas, actividades de reglamentación y sometimiento a la justicia.

${ }^{16}$ Sin ánimo de exhaustividad, como comentarios de esta Ley, vid. Stéphane Brabant / Elsa Savourey, «Scope of the Law on the Corporate Duty of Vigilance. Companies Subject to the Vigilance Obligations», Revue Internationale de la Compliance et de l'étique des affaires, núm. 50, 2017, 1-8; Marie Caroline Caillet, «Du devoir de vigilance aux plans de vigilance: quelle mise en oeuvre?», Droit Social, núm. 10, 2017, 819-827; Nicolas Cuzacq, «Commentaire des propositions de loi relatives au devoir de vigilance des sociétés mères et des enterprises donneuses d'ordre», Revue de Droit du Travail, núm. 4, 2014, 265-266; Anne Danis-Fatôme / Geneviève Viney, «La responsabilité civile dans la loi relative au devoir de vigilance des sociétés mères et des entreprises donneuses d'ordre», Recueil Dalloz, núm. 28, 2017, 1610-1618; Renée Claude Drouin, «Le développement du contentieux à l'encontre des entreprises transnationales: quel rôle pour le devoir de vigilance», Droit social, 2016, 246; Adoración Guamán Hernández, «Diligencia debida en derechos humanos y empresas transnacionales: de la ley francesa a un instrumento internacional jurídicamente vinculante sobre empresas y derechos humanos», Lex Social - Revista Jurídica de los Derechos Sociales, vol. 8, núm. 2, 2018, 216-250; Charley Hannoun, «Le devoir de vigilance des sociétés mères et entreprises donneuses d'ordre après la loi du 27 mars 2017», Droit Social, núm. 10, 2017, 806-818; J. Heinich, «Devoir de vigilance des sociétés mères et des entreprises donneuses d'ordre: une loi finalement adoptée, mais amputée », Droit sociétés, 2017, 78; Peter Herbel, «La responsabilité sociétale de l'entreprise en tant que vecteur pour faire avancer les droits de l'homme par l'entreprise», Recueil Dalloz, 2013, 1570; Kathia Martin-Chenut, «Devoir de vigilance: internormativités et durcissement de la RSE», Droit Social, núm. 10, 2017, 798-805; Maire-Ange Moreau, «L'originalité de la loi françáise du 27 mars 2017 relative au devoir de vigilance dans les chaînes d'approvisionnement mondiales», Droit Social, núm. 10, 2017, 792-797; Béatrice Parance, «La consécration législative du devoir de vigilance des sociétés mères et des entreprises donneuses d'ordre», Gaz. Pal. 18 avr. 2017, núm. 15, 16; Pataut, «Le devoir de vigilance...», 833-839; Tatiana Sachs, «La loi sur le devoir de vigilance des sociétés-méres et sociétés donneuses d'ordre: les ingrédients d'une corégulation», $R \boldsymbol{e}$ vue de Droit du Travail, núm. 6, 2017, 380-390; Jean-Brice Tap, «Le devoir de vigilance, un nouvel horizon», Revue de Jurisprudence Commerciale, janvier / février 2018, 1-12.

17 Vid. Cuzacq, «Commentaire des propositions...», 265-266. 
quedó reducida a una obligación de medios, y no de resultados, dado que para poder hacer responder a la empresa matriz por los daños causados por su filial, era preciso acreditar que la matriz bien no había implementado un obligatorio Plan de Vigilancia, o no lo había ejecutado adecuadamente ${ }^{18}$.

Además, el Tribunal Constitucional francés intervino también para modular aún más los efectos de la Ley en el terreno de las sanciones-multa que se podían imponer a estas empresas ${ }^{19}$, lo que dejó a la Ley muy debilitada.

Pero pese a todas las limitaciones, a día de hoy, la Ley francesa sigue suponiendo un precedente de indiscutible importancia, puesto que impone el deber de vigilancia de las empresas matrices sobre sus filiales y sociedades dependientes, obligando a elaborar y aplicar un Plan de Vigilancia a todas las empresas cuya sede social se encuentre en territorio francés y que al cierre de dos ejercicios financieros consecutivos empleen a al menos 5.000 asalariados en Francia o a al menos 10.000 asalariados en el mundo, en su sede y filiale ${ }^{20}$. En consecuencia, esta Ley se aplicaría a todas las empresas que tengan su sede social en Francia, siempre que cumplan estas características (art. L 225-102-4 Código de Comercio francés), lo que estaría en sintonía con lo establecido por la ley que rige el estatuto jurídico de las personas jurídicas en Francia (lex societatis), ya que según dispone el artículo L 210-3 del Código de Comercio francés, «las sociedades cuya sede social esté situada en territorio francés se someterán a la Ley francesa» ${ }^{21}$.

Para delimitar cuáles son las empresas a las que debe abarcar el Plan de Vigilancia, la Ley utiliza el concepto de control empresarial, directo o

18 Vid. Hannoun, «Le devoir de vigilance...», 809; Durán Ayago, «Sobre la responsabilidad de las empresas...», 337.

19 Conseil constitutionnel $n^{\circ}$ 2017-750 DC de 23 de marzo de 2017, acceso el 20 de enero de 2020, https://www.conseil-constitutionnel.fr/decision/2017/2017750DC.htm. Inicialmente, la Ley establecía la posibilidad de imponer multas civiles por el incumplimiento del Plan de Vigilancia, multa que no podía superar los 10 millones de euros, incorporando también la posibilidad de aumentar hasta tres veces la multa prevista por la condena del infractor a la reparación del daño.

${ }^{20}$ Se ha criticado por parte de las organizaciones de la sociedad civil el ámbito subjetivo de aplicación de la ley, ya que se considera un umbral demasiado alto que deja fuera a numerosas empresas, y se ha planteado que una posible referencia para ampliar su ámbito de aplicación sea atender a la Directiva 2014/95/UE del Parlamento Europeo y del Consejo, de 22 de octubre de 2014 , por la que se modifica la Directiva 2013/34/UE en lo que respecta a la divulgación de información no financiera e información sobre diversidad por parte de determinadas grandes empresas y determinados grupos, que afecta a las empresas con balances de más de 20 millones de euros, un volumen de negocio de más de 40 millones de euros y más de 500 empleados. Vid. https://www.amisdelaterre.org/IMG/pdf/ley-francesa-deber-devigilancia-faq-web-final.pdf, 6, acceso el 21 de enero de 2020.

${ }^{21}$ Pataut, «Le devoir de vigilance...», 835, se cuestiona sobre el alcance real de su ámbito subjetivo de aplicación, puesto que quedarían fuera de su esfera todas las empresas que tuvieran sede en otros países, aunque su sede real estuviera en Francia. 
indirecto, aunque este concepto no se desarrolla específicamente en esta Ley, sino que se realiza una remisión al artículo L 233-3 del Código de Comercio francés ${ }^{22}$. De su regulación se desprende que se aplica a la empresa matriz, a las empresas controladas directa o indirectamente por la empresa matriz y a los subcontratistas y proveedores con los que mantenga una relación comercial consolidada, en los términos del artículo L 442-6, I, 5. ${ }^{\circ}$ del Código de Comercio francés, esto es, que se trate de relaciones profesionales regulares y estables, con o sin contrato, con un determinado volumen de negocio y que razonablemente sean sostenibles en el futuro.

La concreción del deber de vigilancia gira en torno a la elaboración del Plan de Vigilancia, factor clave en el desarrollo de la Ley, que debe incluir los siguientes elementos, a tenor de lo dispuesto en el artículo L 225-102-4 del Código de Comercio francés: a) Un mapa de riesgos con su identificación, análisis y jerarquía; b) Los procedimientos de evaluación regular de la situación de sus filiales, proveedores y subcontratas en relación con el mapa de riesgos; c) Las acciones emprendidas para atenuar los riesgos y prevenir las violaciones de derechos; d) Los mecanismos de alerta frente a los riesgos, establecidos de acuerdo con las organizaciones sindicales representativas y e) Un dispositivo para el seguimiento de las medidas adoptadas y de evaluación de su eficacia.

En definitiva, el Plan debe contener medidas razonables de vigilancia orientadas a identificar riesgos, prevenir violaciones graves de Derechos humanos y libertades fundamentales y proteger la salud y la seguridad de las personas y del medio ambiente. Si la empresa no elabora y publica su Plan de Vigilancia, un juez puede ordenar que lo haga e imponerle sanciones financieras. Estos planes se deben elaborar y aprobar anualmente y deberán ser públicos, adjuntándose a los informes financieros y extrafinancieros de cada año.

${ }^{22}$ Este precepto dispone que «I.-Se considerará que una sociedad controla a otra, para la aplicación de las secciones 2 y 4 del presente capítulo: $1 .{ }^{\circ}$ Cuando posea directa o indirectamente una fracción del capital que le confiera la mayoría de los derechos de voto en las juntas generales de esta sociedad; $2{ }^{\circ}$ Cuando disponga por sí misma de la mayoría de los derechos de voto en esta sociedad en virtud de un acuerdo firmado con otras sociedades o accionistas que no sea contrario al interés de la sociedad; $3 .{ }^{\circ}$ Cuando tenga el control de hecho sobre las decisiones en las juntas generales de esta sociedad, debido a los derechos de voto de los que disponga. $4^{\circ}$ Cuando esté asociada o sea accionista de dicha sociedad, y disponga de la facultad de nombrar o revocar a la mayoría de los miembros de los órganos de administración, dirección o supervisión de la misma. II.-Se presumirá que ejerce este control cuando disponga directa o indirectamente de un porcentaje de derechos de voto superior al 40\%, y siempre que ningún otro socio o accionista posea directa o indirectamente un porcentaje superior al suyo. III.-Para la aplicación de las mismas secciones del presente capítulo, se considerará que dos o varias sociedades que actúen de modo concertado controlarán conjuntamente a otra cuando tengan el control de hecho de las decisiones tomadas en las juntas generales». 
Pero, como apuntábamos, sólo si la omisión de la obligación de vigilancia o su incorrecta ejecución es la causa del daño, la empresa matriz podrá ser considerada responsable directa del daño. Ello implica la necesidad de establecer la relación directa entre el perjuicio causado y, bien la ausencia del Plan de Vigilancia, bien la defectuosa ejecución del mismo, correspondiendo además la carga de la prueba a los demandantes o víctimas que han sufrido el daño, lo que a la postre, puede llegar a complicar su eficacia real.

La Ley contempla la posibilidad de publicar las decisiones judiciales en las que se haga visible la transgresión del deber de vigilancia por parte de una determinada empresa, ya sea por no tener implementado el Plan de Vigilancia, por no ejecutarlo o por no evaluar de forma periódica la puesta en marcha del mismo. Se trataría de mantener una sanción informativa que entroncaría directamente con la reputación de las empresas que, en el actual mundo globalizado de la información, puede tener también importantes consecuencias $^{23}$.

Si la Ley ya nació capitidisminuida, tras tres años de vigencia han ido aflorando algunos puntos débiles, que organizaciones que representan a la sociedad civil se han encargado de denunciar. En este sentido, han constatado que algunas grandes corporaciones francesas aún no han publicado su Plan de Vigilancia, a pesar de su obligación legal de hacerlo; que los Planes de Vigilancia publicados son de escasa calidad y, en muchos casos, en ellos no se identifican de forma clara los riesgos; que se aprecia una débil participación de los accionistas, pese a que la Ley obliga a esta participación y que, en algunos casos, no se describe la cadena de suministro afectada por el Plan. En términos generales, constatan una escasa voluntad de cumplir con la Ley ${ }^{24}$.

Estas mismas organizaciones no gubernamentales han recomendado a las empresas obligadas por esta Ley, así como a las no cubiertas pero que igualmente trabajan en ámbitos de «alto riesgo», a cumplir con la responsabilidad legal de elaborar, publicar e implementar instrumentos de identificación de riesgos y desarrollo de mecanismos de alerta eficaces. Pero son, sin duda, las autoridades públicas francesas las que deben desarrollar un papel más proactivo, poniendo en marcha diversos mecanismos que coadyuvarán a desarrollar y apuntalar los efectos de esta Ley. Entre estos mecanismos, destacan la necesaria publicación de una lista anual de compañías sujetas a esta Ley, dado que, en estos momentos, no existe un listado exhaustivo de las empresas que están sujetas a ella; deberían designar una en-

${ }^{23}$ Tap, «Le devoir de vigilance...», 10; Durán Ayago, «Sobre la responsabilidad de las empresas...», 337.

${ }^{24} \mathrm{Vid}$. https://www.amisdelaterre.org/IMG/pdf/ley-francesa-deber-de-vigilancia-faqweb-final.pdf, acceso el 21 de enero de 2020. 
tidad administrativa encargada de realizar un seguimiento de la aplicación de la Ley, que garantice un acceso centralizado a los Planes de Vigilancia de estas empresas. De lege ferenda, el legislador debería plantearse ampliar, por una parte, el ámbito de aplicación de la Ley, de forma que cubra a más empresas cuyas actividades sean altamente susceptibles de provocar violaciones contra los Derechos humanos y contra el medio ambiente y, por otra parte, revertir la carga de la prueba, esto es, no hacer recaer sobre las víctimas la carga de demostrar la responsabilidad en el daño de la empresa. Y, con carácter más amplio, la sociedad civil le ha pedido a las autoridades francesas que apoyen la extensión de una Ley del deber de vigilancia en la Unión Europea, al tiempo que también aboguen por que en la Unión se apoye la elaboración y adopción del tratado sobre empresas multinacionales y transnacionales y Derechos humanos que actualmente se está negociando en el seno de Naciones Unidas, colaborando activamente con su Grupo de Trabajo ${ }^{25}$. Aunque esta cuestión será complicada pues, por el momento, la Unión Europea no parece estar muy interesada en ello $^{26}$.

\section{Responsabilidad por daños causados por filiales y sociedades dependientes de empresas francesas: incidencia en el sistema de DIPr. europeo}

\section{De dónde venimos y dónde estamos}

En el Informe elaborado por el Parlamento Europeo sobre la responsabilidad de las empresas por violaciones graves de los Derechos humanos en terceros países ${ }^{27}$ se realiza un análisis interesante del contexto en el que nos encontramos. Realista y necesario. En él se señala la carencia en la Unión Europea de un enfoque holístico con respecto a la responsabilidad de las empresas por la violación de los Derechos humanos y denuncia la indefensión a la que las víctimas de estas violaciones se enfrentan, debido a los múltiples obstáculos que existen para acceder a la justicia, no

${ }^{25} \mathrm{Vid}$. Resolución A/HRC/RES/26/9 «Elaboración de un instrumento internacional jurídicamente vinculante sobre las empresas transnacionales y otras empresas con respecto a los derechos humanos»: adoptada con votación en el Consejo de derechos humanos de las Naciones Unidas el 26 junio 2014, acceso el 30 de enero de 2020, https://www.ohchr.org/Documents/HRBodies/HRCouncil/WGTransCorp/Session3/LegallyBindingInstrumentTNCs_ OBEs_SP.pdf.

${ }^{26}$ Vid. Guamán Hernández, «Diligencia debida en derechos humanos...», 246.

27 (2015/2315(INI)) A8-0243/2016, accesible en http://www.europarl.europa.eu/sides/ getDoc.do?pubRef=-//EP//TEXT+REPORT+A8-2016-0243+0+DOC+XML+V0//ES, acceso el 23 de enero de 2020. 
sólo para hallar una posibilidad real de poder demandar a los responsables últimos del daño que se les haya causado, sino también por los obstáculos procedimentales a la admisibilidad y la divulgación de pruebas, los gastos procesales a menudo prohibitivos y la ausencia de normas claras en materia de responsabilidad de las empresas por la violación de los Derechos humanos $^{28}$. En el Informe se recuerda que los Estados, actuando en el ámbito de su jurisdicción, tienen el deber de proteger de forma activa los Derechos humanos, también contra las violaciones cometidas por las empresas, incluso si éstas operan en terceros países, lo que implica la necesidad de garantizar a las víctimas que se encuentren bajo su jurisdicción una vía efectiva de recurso. Para ello es preciso que los Estados miembros legislen de forma coherente, global, eficaz y vinculante con miras a cumplir su obligación de prevenir, investigar y sancionar las violaciones de los Derechos humanos cometidas por empresas bajo su jurisdicción, incluidas las perpetradas en terceros países.

En este sentido, el Parlamento europeo aboga por la construcción de un corpus legislativo coherente, incluidas las normas que rigen el acceso a la justicia, la jurisdicción, el reconocimiento y la ejecución de resoluciones judiciales en materia civil y mercantil, la legislación aplicable y la asistencia judicial en situaciones transfronterizas que impliquen a terceros países. Y alude directamente al Reglamento 1215/2012, de 12 de diciembre de 2012, relativo a la competencia judicial, el reconocimiento y la ejecución de resoluciones judiciales en materia civil y mercantil (en adelante, Reglamento $1215 / 2012)^{29}$, como uno de los principales textos que habría que revisar, por la dificultad que existe con su actual formulación para subsumir acciones efectivas en estos casos, en la idea de introducir las modificaciones necesarias para posibilitarlas ${ }^{30}$.

Son buenos propósitos, sin duda, pero lo cierto es que no han sido muchos los movimientos que se han dado en esta dirección, y a día de hoy, en el seno de la Unión Europea, no resulta sencillo juzgar conjuntamente a la empresa matriz y a su filial domiciliada en un tercer Estado por los daños ocurridos en el Estado de acogida. A este respecto, la Recomendación CM/ Rec(2016)3 sobre derechos humanos y empresas ${ }^{31}$ propone a los Estados

${ }^{28}$ Un análisis pormenorizado de estas dificultades puede verse en Pigrau Solé / Álvarez Torné / Cardesa-Salzmann / Font i Mas / Iglesias Márquez / Jaria i Manzano, Derechos humanos y empresas europeas; Álvarez Rubio / Yiannibas, Human Rights in Business...

29 DO L 351, de 20 de diciembre de 2012.

30 Marta Requejo Isidro, «Access to remedy. Abusos contra Derechos humanos en terceros Estados, ¿justicia civil en Europa», en Zamora Cabot, F. J. / García Cívico, J. / Sales Pallarés, L., La responsabilidad de las multinacionales...», 81 y ss.

31 Acceso el 28 de enero de 2020, https://search.coe.int/cm/Pages/result_details. aspx?ObjectID $=09000016805 \mathrm{c} 1 \mathrm{ad} 4$. 
miembros del Consejo de Europa, como una posible vía para intentar acabar con la impunidad, que permitan que sus tribunales nacionales ejerzan su competencia judicial internacional en casos contra empresas matrices domiciliadas en su jurisdicción, así como contra las filiales domiciliadas en otra jurisdicción cuando las reclamaciones estén estrechamente relacionadas.

Se trataría de esgrimir, como ya hemos apuntado, frente a la personalidad jurídica propia y a la responsabilidad jurídica limitada, el control de dirección y el deber de diligencia, que son dos de los elementos en que se sustenta la Ley francesa. En su desarrollo, el artículo 4 del Reglamento $1215 / 2012$, en que se regula el foro del domicilio del demandado, podría adquirir un renovado papel ${ }^{32}$.

El concepto de deber de diligencia procede del Derecho anglosajón y hace referencia a las medidas que una empresa debe tomar para tener conocimiento, prevenir y responder de los efectos negativos de sus actuaciones sobre los Derechos humanos ${ }^{33}$. Entiende Giner que la debida diligencia implica, en primer lugar, esforzarse por conocer el contexto del país en el que las empresas desarrollan sus actividades y entender las cuestiones relacionadas con los Derechos humanos en ese entorno. Conlleva, además, realizar un diagnóstico de las prácticas y políticas corporativas, así como un análisis objetivo de los efectos reales y potenciales de sus actividades con el objetivo de identificar cuestiones importantes con enfoque en los Derechos humanos. Y supone, al fin, evitar estimular, perpetuar o contribuir a vulneraciones de los Derechos humanos por medio de relaciones vinculadas a sus actividades ${ }^{34}$.

32 Durán Ayago, «Sobre la responsabilidad de las empresas...», 340.

${ }^{33}$ Informe del Representante Especial del Secretario General sobre la cuestión de los derechos humanos y las empresas transnacionales y otras empresas comerciales, John Ruggie, Adición - Resumen de cinco reuniones de consulta con múltiples interesados, A/HRC/8/16, acceso el 22 de enero de 2020, https://observatoriorsc.org/wp-content/uploads/2013/11/Proteger_respetar_remediar_abril2008.pdf.

34 Agnes Giner, «Las empresas transnacionales y los Derechos Humanos», Law Harremanak 19 (2008-II), 79. En el ámbito de la Unión Europea, el deber de diligencia ha sido plasmado hasta el momento en la Directiva 2014/95/UE del Parlamento Europeo y del Consejo, de 22 de octubre de 2014, por la que se modifica la Directiva 2013/34/UE en lo que respecta a la divulgación de información no financiera e información sobre diversidad por parte de determinadas grandes empresas y determinados grupos [DO L 330, de 15 de noviembre de 2014]. Esta Directiva ha sido incorporada recientemente a nuestro ordenamiento jurídico a través del Real Decreto-ley 18/2017, de 24 de noviembre, por el que se modifican el Código de Comercio, el texto refundido de la Ley de Sociedades de Capital aprobado por el Real Decreto Legislativo 1/2010, de 2 de julio, y la Ley 22/2015, de 20 de julio, de Auditoría de Cuentas, en materia de información no financiera y diversidad [BOE núm. 287, de 25 de noviembre de 2017]. También contiene esta obligación el Reglamento (UE) 2017/821 del Parlamento Europeo y del Consejo de 17 de mayo de 2017, por el que se establecen obligaciones en materia de diligencia debida en la cadena de suministro por lo que respecta a los importadores de la Unión de estaño, tantalio y wolframio, sus minerales y oro originarios de zonas de conflicto o de alto riesgo [DO L130, de 19 de mayo de 2017]. 
Por su parte, el control de dirección se plasma de forma diversa en cada ordenamiento jurídico, pero hace referencia al control económico, financiero y administrativo que la empresa matriz suele tener sobre sus filiales. Demostrar el control de dirección de la empresa matriz sobre la filial causante del daño puede suponer un elemento determinante para imputar la responsabilidad directamente a la empresa matriz, con todo lo que ello puede conllevar para hacer realidad el resarcimiento del daño causado.

Aunque Ley francesa reguladora del deber de vigilancia no introduce ninguna disposición de DIPr., su alcance para las normas de DIPr. está fuera de toda duda, tanto a la hora de la precisión de los foros de competencia judicial internacional, como para determinar el Derecho aplicable a la responsabilidad civil derivada del daño causado en el ejercicio de las actividades del grupo de empresas. No vamos a detenernos aquí en el análisis de la competencia judicial internacional y los ajustes necesarios que habría que llevar a cabo en el Reglamento 1215/2012 para que la forzada interpretación y la discrecionalidad judicial dejaran de ser los artífices de una correcta modulación de las acciones que se pudieran presentar en este sentido en los Estados miembros de la Unión ${ }^{35}$. Vamos a detenernos, en cambio, en precisar el diálogo que debe entablarse entre la lex societatis y la lex damni para una correcta determinación del derecho aplicable que redunde en el interés de las víctimas o, dicho con otras palabras, que posibilite el resarcimiento del daño en toda su extensión.

\section{Responsabilidad social empresarial y lex societatis: el debate necesario}

Como venimos apuntando, la Ley francesa del deber de vigilancia se incardina dentro de un contexto global que exige la necesidad de elaborar un marco normativo que limite la actuación de las empresas multinacionales y transnacionales. Abogan por ello el Pacto Mundial de las Naciones Unidas (Global Compact), en el que se solicita a estas empresas que, dentro de su esfera de influencia, adopten, apoyen y apliquen un conjunto de valores centrales en materia de Derechos humanos, normas laborales, medio ambiente y lucha contra la corrupción, mediante un compromiso con estos valores y su integración en la actividad empresarial con carácter voluntario ${ }^{36}$. En la misma senda están los Principios rectores sobre las Empresas y los Derechos Humanos de Naciones Unidas (ONU, 2011) (los denominados Prin-

35 Remitimos a nuestro trabajo Durán Ayago, «Sobre la responsabilidad de las empresas...», 339-342 y la bibliografía allí citada.

36 Acceso el 28 de enero de 2020, https://www.unglobalcompact.org/what-is-gc/mission/ principles. 
cipios Ruggie) ${ }^{37}$; las Líneas Directrices para Empresas Multinacionales de la Organización para la Cooperación y el Desarrollo Económico (OCDE, 2011) $)^{38}$; la Declaración Tripartita de Principios sobre las Empresas Multinacionales y la Política Social de la Organización Internacional del Trabajo $(\mathrm{OIT}, 1977)^{39} \mathrm{y}$, en el ámbito específico del sector extractivo, los Principios Voluntarios de Seguridad y Derechos Humanos $(2000)^{40}$. En el contexto europeo, el ya citado Informe sobre la responsabilidad de las empresas por violaciones graves de los derechos humanos en terceros países camina en la misma línea ${ }^{41}$. Todos ellos inciden en la necesidad que incorporar a la responsabilidad social de las empresas su compromiso con los Derechos humanos $^{42}$. De hecho, no parece posible plantearse una política de responsabilidad social empresarial válida sin tomar como referente los Derechos humanos ${ }^{43}$. En este sentido, y aunque es difícil encontrar un concepto unívoco de responsabilidad social empresarial ${ }^{44}$, el Consejo Empresarial Mundial para el Desarrollo Sostenible la ha definido como el compromiso continuo de la empresa de actuar éticamente y de contribuir al crecimiento económico, al mismo tiempo que mejora la calidad de la fuerza laboral, así como de las comunidades locales y de la sociedad en general ${ }^{45}$.

En la Estrategia renovada de la Unión Europea para 2011-2014 sobre la responsabilidad social de las empresas ${ }^{46}$, se señala que el respeto de la

37 Acceso el 28 de enero de 2020, https://www .ohchr.org/documents/publications/guidingprinciplesbusinesshr_sp.pdf.

38 Acceso el 28 de enero de 2020, https://www.oecd.org/daf/inv/mne/MNEguidelinesESPANOL.pdf.

39 Acceso el 28 de enero de 2020, https://www.ilo.org/empent/Publications/ WCMS_124924/lang--es/index.htm.

40 Acceso el 28 de enero de 2020 https://www.international-alert.org/publications/principios-voluntarios-en-seguridad-y-derechos-humanos.

${ }^{41}$ Vid. Carmen Márquez Carrasco / Inmaculada Vivas Tesón (coords.), La implementación de los Principios rectores de las Naciones Unidas sobre empresas y derechos humanos por la Unión Europea y sus Estados miembros, Thomson Reuters Aranzadi, Navarra, 2017.

42 Vid. Olga Martín-Ortega, Empresas multinacionales y Derechos Humanos en Derecho Internacional, Bosch Internacional, Barcelona, 2008, 135 y ss.

${ }^{43}$ María Prandi / Josep María Lozano, Guía práctica de derechos humanos para empresas, Escola de Cultura de Pau (UAB) - ESADE, Barcelona, 2006, p. 16.

44 Vid. Martín-Ortega, Empresas multinacionales..., 207 y ss.

45 World Business Council for Sustainable Development, Corporate Social Responsibility: Meeting changing expectations, Ginebra, 1999, 6. Adela Cortina va más allá en su tribuna en el Diario El País, «Ética de la empresa, no sólo responsabilidad social», publicada el 20 de agosto de 2005, acceso el 28 de enero de 2020, https://elpais.com/diario/2005/08/20/ opinion/1124488806_850215.html. La misma idea desarrollada en artículo académico en Revista Portuguesa de Filosofia, t. 65, fasc. 1, 2009, 113-127.

46 Estrategia renovada de la Unión Europea para 2011-2014 sobre la responsabilidad social de las empresas. Comunicación de la Comisión al Parlamento Europeo, al Consejo, al Comité Económico y Social Europeo y al Comité de las Regiones, Bruselas, 25.10.2011 
legislación aplicable y de los convenios colectivos entre los interlocutores sociales es un requisito previo al cumplimiento de dicha responsabilidad. Para asumir plenamente su responsabilidad social, las empresas deben aplicar, en estrecha colaboración con las partes interesadas, un proceso destinado a integrar las preocupaciones sociales, medioambientales y éticas, el respeto de los Derechos humanos y las preocupaciones de los consumidores en sus operaciones empresariales y su estrategia básica, a fin de maximizar la creación de valor compartido para sus propietarios/accionistas y para las demás partes interesadas y la sociedad en sentido amplio, además de identificar, prevenir y atenuar sus posibles consecuencias adversas.

De esta manera, la responsabilidad social empresarial abarca, como mínimo, los Derechos humanos, las prácticas de trabajo y de empleo (como la formación, la diversidad, la igualdad de género y la salud y el bienestar de los trabajadores), las cuestiones medioambientales (como la biodiversidad, el cambio climático, el uso eficiente de los recursos, la evaluación del ciclo de vida y la prevención de la contaminación) y la lucha contra el fraude y la corrupción. La participación de las comunidades locales y el desarrollo, la integración de las personas con discapacidad y los intereses de los consumidores, incluida la intimidad, forman parte también de la agenda sobre la responsabilidad social corporativa ${ }^{47}$.

En este contexto, de interiorización de la responsabilidad social empresarial, un hándicap añadido es integrar este concepto de manera real en lo que supone la globalización ${ }^{48}$. Algo que consigue la Ley francesa del deber de vigilancia. La cuestión es discernir si la responsabilidad social empresarial se integra dentro del estatuto jurídico de la empresa y quedaría sujeta, por tanto, a la lex societatis, o se trata de una cuestión diferenciada, en cuyo caso, habría que encontrarle un acomodo adecuado, o crear una norma de conflicto específica para este nuevo concepto jurídico.

Para posicionar convenientemente el debate, es menester comenzar sosteniendo que la ley que rige la vida interna de la sociedad (lex societatis) es una única ley estatal ${ }^{49}$. Ley que puede concretarse atendiendo fun-

$\operatorname{COM}(2011) 681$ final, acceso el 22 de enero de 2020, https://eur-lex.europa.eu/legal-content/ ES/TXT/PDF/?uri=CELEX:52011DC0681\&from=ES. De interesante consulta también la Estrategia española de responsabilidad social de las empresas. Acceso el 28 de enero de 2020, http://www.mitramiss.gob.es/ficheros/rse/documentos/eerse/EERSE-Castellano-web.pdf.

47 Supra, 8.

48 Jean-Philippe Robé, Le temps du monde de l'enterprise: globalisation et mutation $d u$ système juridique, Dalloz, 2016.

49 Alfonso Luis Calvo Caravaca / Javier Carrascosa González, Derecho internacional privado, vol. II, Editorial Comares, 2018, 868. En concreto, sobre el estatuto regulador de los grupos de empresas, vid. José Carlos Fernández Rozas / Rafael Arenas García / Pedro Antonio de Miguel Asensio, Derecho de los negocios internacionales, Madrid, Iustel, 6. ${ }^{\text {a }}$ ed. 2020, 235-236. 
damentalmente a dos variables, la subjetiva y la objetiva. Dentro de la primera, englobada dentro de un sistema contractualista, son los socios los que eligen la ley aplicable a la sociedad, bien optando por la teoría de la incorporación, en que la sociedad se rige por la ley del Estado con arreglo a cuya legislación se constituye, bien por la teoría de la sede estatutaria, en que la sociedad se rige por ley del país en que los socios fijan, libremente, el domicilio de la sociedad a efectos civiles. El otro sistema para concretar la ley aplicable a la sociedad es el sistema objetivo de determinación de la ley aplicable o modelo de la sede real, en el cual los socios no pueden elegir la ley, sino que se rige por ley del país con el que la sociedad presenta los vínculos más estrechos, bien atendiendo a la sede de dirección; a la del centro de explotación; a la del lugar de constitución o la del control económico ${ }^{50}$.

La lex societatis regula todas las cuestiones relativas a la vida de la sociedad en sí misma, esto es, su constitución, funcionamiento y extinción. También las cuestiones relativas a las relaciones internas societarias, esto es, las relaciones jurídicas de los socios entre sí y las relaciones entre los socios y los administradores sociales. Y las cuestiones relativas al status legal de la sociedad en sus relaciones externas, tales como la capacidad de la sociedad y la responsabilidad jurídica de la sociedad.

La lex societatis regula, además, la responsabilidad patrimonial de la sociedad, esto es, determina la cuestión de saber si la sociedad responde sólo con sus bienes o si la responsabilidad de la sociedad alcanza o no, y en qué grado, al patrimonio de los socios; también si puede procederse al levantamiento del velo societario, de modo que pueda dirigirse contra los socios, personalmente, la responsabilidad en la que ha incurrido la sociedad ${ }^{51}$.

Es cierto que el concepto de responsabilidad social empresarial no encaja exactamente en el concepto de responsabilidad jurídica de la sociedad o empresa. La responsabilidad social va más allá de la responsabilidad jurídica, pero, en algunos casos, puede y debe ir unida indisolublemente a ella. De hecho, es lo que la Ley francesa posibilita. No es que esta Ley regule íntegramente y con carácter vinculante las cuestiones que deben integrar la responsabilidad social de las empresas con sede social en Francia, pero sí establece una obligación, la de elaborar un Plan de Vigilancia, siendo esta una de las cuestiones que integran su responsabilidad social. De manera que todas aquellas empresas que obligadas a ello no lo hagan, estarán incurriendo en responsabilidad jurídica, lo que va a

${ }^{50}$ Luis Fernández de la Gándara / Alfonso-Luis Calvo Caravaca, Derecho Mercantil internacional, Editorial Tecnos, 1995.

${ }^{51}$ Calvo Caravaca / Carrascosa González, Derecho internacional privado, 873. 
poder traer aparejadas sanciones que pueden ir más allá de ese incumplimiento, puesto que por este motivo se les podrá imputar el daño causado en terceros Estados por sus filiales y sociedades dependientes. Por tanto, la responsabilidad social empresarial en Francia también conlleva responsabilidad jurídica, y, por ello, a mi juicio, debe incardinarse en la lex societatis.

Pero ha de tenerse en cuenta, además, que hablamos de grupos de empresas. Existe un grupo de empresas cuando una sociedad ostente o pueda ostentar, directa o indirectamente, el control de otra u otras. De manera que ha de existir, de un lado, una relación de dependencia, directa o indirecta, de una o varias sociedades con respecto de otra, y, de otro lado, se ha de ejercer una dirección económica única por la empresa matriz sobre el conjunto de las demás. En el caso de filiales, cada sociedad tendrá su propia ley reguladora, si bien, debería ser la ley reguladora de la empresa matriz la que fije las pautas de la responsabilidad social del grupo ${ }^{52}$.

Para Pataut, someter la responsabilidad social empresarial a la lex societatis es, en cierto modo, devaluar lo que implica este concepto, pues se va a hacer depender de la voluntad de los socios, ya que son estos los que pueden decidir dónde fijar la sede social de su empresa ${ }^{53}$. A su juicio, esta Ley debería poder aplicarse, como ley de policía, incluso a empresas que no tengan sede social en Francia, si su sede real sí está en este país ${ }^{54}$. Considera que la regulación de la responsabilidad social empresarial debería integrarse en una nueva norma de conflicto, tal y como se deduce del artículo 1, apartado tercero de la Propuesta sobre ley aplicable a las sociedades, elaborada por el Grupo Europeo de Derecho Internacional Privado, en su encuentro de Milán, del 16 al 18 de septiembre de $2016^{55}$, que establece que «[e]

52 En cuanto al control de dirección, y por citar el ejemplo de la legislación española, el artículo 42 del Código de Comercio, establece que se presumirá que existe control cuando una sociedad, que se califica como dominante, se encuentre en relación con otra sociedad, que se calificará como dependiente, en alguna de las siguientes situaciones: a) Posea la mayoría de los derechos de voto. b) Tenga la facultad de nombrar o destituir a la mayoría de los miembros del órgano de administración. c) Pueda disponer, en virtud de acuerdos celebrados con terceros, de la mayoría de los derechos de voto. d) Haya designado con sus votos a la mayoría de los miembros del órgano de administración, que desempeñen su cargo en el momento en que deban formularse las cuentas consolidadas y durante los dos ejercicios inmediatamente anteriores. En particular, se presumirá esta circunstancia cuando la mayoría de los miembros del órgano de administración de la sociedad dominada sean miembros del órgano de administración o altos directivos de la sociedad dominante o de otra dominada por ésta.

53 Pataut, «Le devoir de vigilance...», 835-836.

54 Pataut, «Le devoir de vigilance...», 836.

55 Acceso el 20 de enero de 2020, https://www.gedip-egpil.eu/documents/Milan\%20 2016/GEDIPs\%20Proposal\%20on\%20Companies.pdf 
l presente Reglamento no prejuzga el cumplimiento de las obligaciones derivadas de la responsabilidad social de las empresas tal como se define en las normas nacionales, europeas o internacionales ${ }^{56}$.

En realidad, según señala Garcimartín, este precepto es el resultado de la falta de consenso sobre el significado y el alcance del concepto de responsabilidad social empresarial, por un lado, y la dificultad de encontrar una norma adecuada de conflicto de leyes para abordarlo, por otro ${ }^{57}$. De ahí esta solución intermedia que no cierra el debate, sino que lo deja abierto en toda su extensión ${ }^{58}$.

\section{El encaje del deber de vigilancia en la lex damni}

En este complejo escenario surge inmediata la cuestión de desentrañar si la Ley francesa sobre el deber de vigilancia entraría dentro de lo que es en sentido estricto la responsabilidad social de las empresas y se enmarcaría en consecuencia dentro de la lex societatis, o si, por el contrario, cabe subsumirla en el Derecho que regula el daño causado, esto es, en la norma que regula la responsabilidad civil.

La norma de conflicto que en la Unión Europea regula la responsabilidad civil es el Reglamento (CE) 864/2007 del Parlamento Europeo y del Consejo, de 11 de julio de 2007, relativo a la ley aplicable a las obligaciones extracontractuales («Roma II») (en adelante, Reglamento Roma II) ${ }^{59}$. $\mathrm{Su}$ artículo $1.2 \mathrm{~d}$ ) expresamente excluye de su ámbito de aplicación material «las obligaciones extracontractuales que se deriven del Derecho de sociedades, asociaciones y otras personas jurídicas, relativas a cuestiones como la constitución, mediante registro o de otro modo, la capacidad jurídica, el funcionamiento interno y la disolución de sociedades, asociaciones y otras personas jurídicas, de la responsabilidad personal de los socios $y$ de los administradores como tales con respecto a las obligaciones de la sociedad $u$ otras personas jurídicas y de la responsabilidad personal de los

${ }^{56}$ Su versión original: «This Regulation does not prejudice the fulfilment of the obligations deriving from social responsibility of companies (corporate social responsibility) as defined by national, European or international norms».

57 Francisco J. Garcimartín Alférez, «The Law Applicable to Companies in the European Union. A Proposal by the European Group for Private International Law» (October 21, 2016), 15-16. Acceso 29 de enero de 2020, https://ssrn.com/abstract=2857077 o http://dx.doi. org/10.2139/ssrn.2857077.

58 Maka Mahbuba Mammadova, «The Law Applicable to Attribution of Conduct and Veil Piercing. From a Single Parent Company to Global Corporations», Studi Europene, núm. 14, 2019, 102-164.

59 DO L 199, de 31 de julio de 2007. 
auditores frente a una sociedad o sus socios en el control legal de los documentos contables» ${ }^{60}$.

Partimos de la base de que en el tema que analizamos esta exclusión no sería aplicable, puesto que, aunque la responsabilidad social de las empresas quede regulada por la lex societatis, la exclusión que se deduce del artículo $1.2 \mathrm{~d}$ ) tiene que ver con la responsabilidad extracontractual que se derive para con la propia sociedad, no, entendemos, respecto de los daños que la incorrecta implementación de una ley como la que analizamos pueda causar a terceros ${ }^{61}$. O, dicho con otras palabras, la exclusión que se realiza en el citado artículo del Reglamento afectaría a aquellas cuestiones relacionadas íntegramente con la sociedad en cuestión, y, en consecuencia, no se entenderían excluidos los daños que dicha sociedad pueda provocar a terceros, aun cuando la imputación concreta de estos daños pueda producirse en virtud de una ley que regula la responsabilidad social empresarial.

Realmente, consideramos que la Ley francesa está a caballo entre ambas regulaciones (lex societatis / lex damni), puesto que es cierto que la Ley del deber de vigilancia impone obligaciones a las empresas que tienen sede social en Francia, a saber, la elaboración y correcta aplicación de un Plan de Vigilancia relativo a las actividades de la empresa principal, sus filiales y las sociedades que controla, así como a las de los proveedores y subcontratistas con los que mantenga una relación comercial regular. Pero si se causa un daño y es posible relacionarlo bien con la falta del Plan de Vigilancia, bien con su defectuosa aplicación, la empresa matriz será responsable junto con su subordinada del daño causado, por lo que en este sentido, ambas cuestiones, ley reguladora de la empresa, como ley reguladora del daño, deben plantearse en estrecha vinculación ${ }^{62}$.

Ahora bien, si está claro que la ley que regula la exigencia de establecimiento del Plan de Vigilancia y su correcta ejecución es la ley francesa, en tanto, lex societatis, ¿qué ley será la que regule la responsabilidad civil?

El Reglamento Roma II señala como regla general, a falta de elección de ley, la lex damni (art. 4), a no ser que se trate de daños sobre el medioambiente, en cuyo caso el artículo 7 ofrece una regulación específica.

60 Vid. Peter Huber (dir.), Rome II Regulation. Pocket Commentary, European Law Publishers, 2011, 48-50.

61 Vid. European Commission, Study on the Law Applicable to Companies, Final Report, 2017, pp. 191 y ss., acceso el 23 de enero de 2020, https://publications.europa.eu/en/publication-detail/-/publication/259a1dae-1a8c-11e7-808e-01aa75ed71a1/language-en.

62 Pataut, «Le devoir de vigilance...», 837. 
La articulación del artículo 7, permitiendo elegir a la víctima entre la ley del Estado en que se ha generado el daño y la ley del Estado en que se ha manifestado, ofrece a la víctima, en el concreto caso de un daño causado por una empresa subordinada de una matriz francesa, la posibilidad de elegir la ley del Estado de acogida o la ley francesa, si entendemos que el hecho generador del daño se ha producido en Francia por una incorrecta aplicación de la Ley francesa del deber de vigilancia. Esta autonomía de la voluntad limitada resulta positiva, porque podrá elegirse el Derecho más eficiente en términos jurídicos desde la perspectiva de la víctima ${ }^{63}$.

Sin embargo, en el caso de que nos hallemos ante otro tipo de daños diferentes a los medioambientales, el artículo 4 daría como solución aplicar la ley del Estado de acogida, que no suele ser la más idónea en estos casos, por lo que más atrás ya hemos analizado. En este escenario, cabrían dos hipótesis de resolución ${ }^{64}$ : bien considerar la cláusula de excepción que contempla el último apartado del artículo 4, teniendo en cuenta que el litigio está estrechamente vinculado con el Estado francés, pues el daño causado emana de una incorrecta aplicación del Plan de Vigilancia al que está obligado la matriz francesa, o bien apelar al artículo 9 del Reglamento Roma II, considerando a la Ley francesa del deber de vigilancia como una norma de policía ${ }^{65}$. En el primer caso, se aplicaría el Derecho de responsabilidad francés en su conjunto, mientras que, en el segundo, recurrir a la articulación de la Ley del deber de vigilancia como ley de policía, supondría la necesaria coordinación de la ley francesa y la ley del Estado de acogida donde ha tenido lugar el daño, lo que complicaría a la postre la solución final ${ }^{66}$.

Esta podría ser una solución derivada de una interpretación posible del contexto actual que tenemos. Pero no está de más exigir cambios que desde el sistema europeo de DIPr. acompañen al cambio que necesariamente se está produciendo paulatinamente en los derechos materiales, exigiendo de manera vinculante a las empresas compromisos reales con el respeto a los Derechos humanos.

${ }^{63}$ En sentido crítico a la operatividad real del artículo 7, vid. Eduardo Álvarez-Armas, «Daños al medioambiente y Derecho internacional privado europeo: ¿quid de la determinación de la ley aplicable como herramienta de gobernanza global medioambiental?», Anuario español de Derecho internacional privado, t. XVIII, 2018, 193-225.

${ }^{64}$ Vid. interesante argumentación sobre ambas posibilidades en Pataut, «Le devoir de vigilance...», 838-839.

65 Por esta última vía se inclina el diputado D. Potier en el Informe presentado ante la Asamblea francesa, Assemblée Nationale, $\mathrm{N}^{\circ} 2628 \ldots$, loc. cit.

${ }^{66}$ Hasta aquí hemos reproducido casi fielmente las ideas expuestas en Durán Ayago, «Sobre la responsabilidad de las empresas...», 343-344. 
$\mathrm{Y}$ en este sentido consideramos que es necesario que la responsabilidad social de la empresa figure enmarcada dentro de su estatuto jurídico. Proponer su desmembración, indicando que sea una ley diferente de la lex societatis la que la regule, supone, de alguna manera, considerar esta cuestión como ajena a la propia empresa. Y esto, a mi juicio, es un error. Otra cosa es que la obligatoriedad de su contenido, impuesta por el Estado o por la Unión Europea, llegado el momento, exija una articulación adecuada, de manera que el concepto de la autonomía de la voluntad de los socios en la conformación de la personalidad jurídica de la empresa no determine únicamente esta cuestión. Bastaría con establecer la obligatoriedad de un mínimo de exigencia en el respeto a los Derechos humanos, de manera que se indique que todas las empresas con sede estatutaria o sede real en un determinado Estado están obligadas a respetar ese mínimo, con independencia de que la lex societatis determine un nivel de responsabilidad social mayor. No es este el caso, en principio, de la Ley francesa, pues el legislador ha decidido limitar el ámbito de aplicación de esta Ley únicamente a las empresas que tengan sede social en Francia y cumplan con los requisitos que ya apuntamos. No olvidemos que son estas las empresas que se rigen por el Derecho francés, en tanto lex societatis. La idea sería poder extender el nivel mínimo de exigencia en materia de responsabilidad social a todas aquellas empresas que realmente operen en un determinado Estado, en tanto norma de imperativo cumplimiento. De esta manera, el Estado en que la sociedad opere marcaría su política vinculante en el respeto a los Derechos humanos, sin perjuicio de que la lex societatis pudiera fijar un nivel de compromiso superior. Podría ser un buen punto de partida.

Una vez configurada la responsabilidad social de la empresa, es obvio que todo puede resultar más sencillo de articular, incluso respecto de los grupos de empresas, puesto que, si las filiales de estas empresas causan un daño, directamente podría remitir a la lex societatis, puesto que va a ser la que establezca obligaciones para el grupo. De manera que la lex damni se transustanciaría en la lex societatis, como ley real para exigir y regular la responsabilidad. La ley del lugar en donde ha ocurrido el hecho dañoso realmente se convertiría en secundaria. Se rompería el factor de desprotección y haría que todas las empresas con sede en Estados que implementen con carácter vinculante políticas de responsabilidad social empresarial, fueran responsables por los daños causados en cualquier parte del mundo, según el derecho que las regula, que es el único derecho indubitado, con el que están estrechamente vinculadas y del que no pueden escapar. Así, lex damni y lex societatis se identificarían actuando como un poderoso mecanismo para romper la impunidad de los grandes grupos empresariales. 


\section{A modo de conclusión}

Empresas matrices, filiales, Derechos humanos, deber de vigilancia, control de dirección, responsabilidad social empresarial, ética de los negocios, responsabilidad civil, lex societatis, lex damni. Y las víctimas. Y su derecho a la tutela judicial efectiva y a una real reparación del daño causado.

Durante demasiado tiempo, la globalización ha conseguido que la ley del más fuerte sea una verdad indiscutida e inapelable. El Derecho mercantil ha desempeñado eficazmente su papel y ha limitado la responsabilidad de las empresas. Las reglas de la personalidad jurídica propia y la responsabilidad jurídica separada han sido elevadas a máximas indiscutibles. Y los grandes grupos empresariales han hecho de ella su bandera para su expansión y fortalecimiento.

Han tardado en llegar las reivindicaciones de justicia, con los Derechos humanos reclamando un papel protagónico que hasta el momento la globalización no ha querido darles. Pero la realidad comienza a ser otra. Y debe llegar a ser otra totalmente distinta de la que ahora tenemos. Por ahora, sólo se vislumbran algunos pasos relevantes, pero es claro que aún queda camino por recorrer.

Al Derecho le cuesta reaccionar, más cuando existen claras hostilidades para que lo haga. Pero es claro que sobre la regulación de los grupos internacionales de empresas se ha extendido un silencio en el legislador llamativo. Y es preciso dar pasos para abordar su correcta regulación, si es que pretendemos lograr un Derecho también para quienes se ven afectados por las decisiones de estas grandes empresas. En este sentido, la Ley francesa del deber de vigilancia decidió dar el paso, y aunque con zancadillas, ha abierto camino para los que necesariamente habrán de venir. Pero también ha puesto de manifiesto que no sólo en el Derecho mercantil es preciso llevar a cabo reformas, también en el DIPr.

En este sentido, además de orientar el sistema europeo de competencia judicial internacional a posibilitar acciones contra las empresas que tengan sede en la Unión Europea, aunque los daños se hayan causado en terceros Estados por sus filiales o empresas dependientes, otra de las cuestiones de interés es determinar el derecho a aplicar en estos casos, puesto que la actual formulación del Reglamento Roma II basada en la lex damni, lleva con carácter general a la aplicación de la ley del Estado de acogida, que no resulta ser la más efectiva para los derechos de las víctimas.

Es verdad que la cláusula de los vínculos más estrechos (art. 4.3 Reglamento Roma II), puede facilitar la aplicación del Estado en que se encuentra domiciliada la empresa matriz, pero también cabría reflexionar si en estos casos, la lex societatis en su integridad tiene algo que decir, algún papel que desarrollar. Es cuestión todavía debatida si realmente la responsabili- 
dad social de las empresas debe quedar regulada por la lex societatis. Como hemos expuesto en este trabajo, consideramos que lo idóneo es que así sea, como forma de interiorizar esta responsabilidad y considerarla un elemento más de su estatuto jurídico. La Ley francesa del deber de vigilancia se enmarca en esta senda. Establece un deber vinculante de vigilancia a las empresas que tengan su sede social en Francia y cumplan con un mínimo de trabajadores contratados. La responsabilidad por su incumplimiento podrá ser meramente interna, de la que se derivarán una serie de sanciones-multa para la empresa, o puede ser externa, en la medida en que a consecuencia de la omisión del deber de vigilancia o de su incorrecta ejecución se derive un daño causado por una de las filiales o sociedades dependientes asentadas en terceros Estados. Es en estos casos, cuando es importante hacer dialogar a la lex damni y a la lex societatis. Y ello porque el daño surge de la responsabilidad social de las empresas, o, mejor dicho, del incorrecto ejercicio de esta responsabilidad. Al final, la solución más eficiente es la transustanciación de la lex damni en la lex societatis, porque el daño realmente deriva de su carencia de responsabilidad social. Será esta ley también la que en estos casos posibilite un correcto resarcimiento del daño.

En todo caso, estas son sólo algunas ideas sobre lo que habrá de venir. Mucho camino aún por recorrer en esta materia para el DIPr., pero es menester comenzar a andarlo ya, puesto que su interlocución en estos casos es determinante.

\section{Sobre la autora}

Antonia Durán Ayago es Profesora Titular de Derecho Internacional Privado en la Universidad de Salamanca. Licenciada y Doctora en Derecho por la Universidad de Extremadura con Premio Extraordinario (2004). Ha publicado dos monografías, La protección internacional del menor desamparado: régimen jurídico (Colex, 2004) y La protección de las pymes en el comercio internacional: propuestas de regulación (Atelier, 2008). Y es coautora de los siguientes libros: Guía Legal Práctica de Extranjería (Comares, 2006); Curso de Nacionalidad y Extranjería (Colex, última edición 2008) y Aplicación práctica del Derecho internacional privado: casos y soluciones (Ratio Legis, última edición 2015). Ha escrito además numerosos artículos y capítulos de libros sobre distintas cuestiones del Derecho internacional privado, fundamentalmente en materia de Derecho de familia. Obtuvo el XV Premio La Ley de artículos doctrinales para profesionales del Derecho con el artículo «La filiación adoptiva en el ámbito internacional» (2001). Ha promovido la Clínica Jurídica de Acción Social de la USAL y la ha dirigido desde su creación en 2016 hasta 2019. 


\begin{abstract}
About the autor
Antonia Durán Ayago is Associate Professor of Private Internacional Law at the University of Salamanca. PhD of Law from the University of Extremadura with Extraordinary Prize (2004). He has published two monographs, The international protection of homeless minors: legal regime (Colex, 2004) and The protection of SMEs in international trade: regulatory proposals (Atelier, 2008). And she is the co-author of the following books: Legal Practical Guide to Immigration (Comares, 2006); Course on Nationality and Immigration (Colex, last edition 2008) and Practical application of private international law: cases and solutions (Ratio Legis, last edition 2015). He has also written numerous articles and book chapters on different issues of Private International Law, mainly in matters of Family Law. He obtained the XV Prize «La Ley» on doctrinal articles for legal professionals with the article «International adoption « (2001). She has promoted the Legal Clinic of Social Action of the University of Salamanca and has directed it from its creation in 2016 to 2019.
\end{abstract}




\section{Derechos de autor}

Los derechos de autor (para la distribución, comunicación pública, reproducción e inclusión en bases de datos de indexación y repositorios institucionales) de esta publicación (Cuadernos Europeos de Deusto, CED) pertenecen a la editorial Universidad de Deusto. El acceso al contenido digital de cualquier número de Cuadernos Europeos de Deusto es gratuito inmediatamente después de su publicación. Los trabajos podrán leerse, descargarse, copiar y difundir en cualquier medio sin fines comerciales y según lo previsto por la ley; sin la previa autorización de la Editorial (Universidad de Deusto) o el autor. Así mismo, los trabajos editados en CED pueden ser publicados con posterioridad en otros medios o revistas, siempre que el autor indique con claridad y en la primera nota a pie de página que el trabajo se publicó por primera vez en CED, con indicación del número, año, páginas y DOI (si procede). Cualquier otro uso de su contenido en cualquier medio o formato, ahora conocido o desarrollado en el futuro, requiere el permiso previo por escrito del titular de los derechos de autor.

\section{Copyright}

Copyright (for distribution, public communication, reproduction and inclusion in indexation databases and institutional repositories) of this publication (Cuadernos Europeos de Deusto, CED) belongs to the publisher University of Deusto. Access to the digital content of any Issue of Cuadernos Europeos de Deusto is free upon its publication. The content can be read, downloaded, copied, and distributed freely in any medium only for non-commercial purposes and in accordance with any applicable copyright legislation, without prior permission from the copyright holder (University of Deusto) or the author. Thus, the content of CED can be subsequently published in other media or journals, as long as the author clearly indicates in the first footnote that the work was published in CED for the first time, indicating the Issue number, year, pages, and DOI (if applicable). Any other use of its content in any medium or format, now known or developed in the future, requires prior written permission of the copyright holder. 